\title{
Hurricane Florence Makes Landfall in the Southeast USA: Sensitive Dependence on Initial Conditions, Parameterizations, and Integrated Enstrophy
}

\author{
Sarah S. Balkissoon'1, Jonathan T. Bongard1, Thomas Cain¹, Dominic M. Candela1, Corey Clay1,

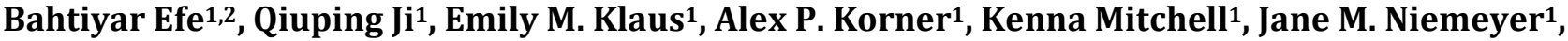 \\ Jordan L. Rabinowitz ${ }^{1}$, Samuel P. Ritter ${ }^{1}$, Katherine Rojas ${ }^{1}$, Paula Sumrall1', Patrick S. Market1, \\ Anthony R. Lupo ${ }^{1}$
}

\author{
${ }^{1}$ Atmospheric Science Program, School of Natural Resources, University of Missouri, Columbia, MO, USA \\ ${ }^{2}$ Department of Meteorological Engineering, Samsun University, Samsun, Turkey \\ Email: lupoa@missouri.edu
}

How to cite this paper: Balkissoon, S.S., Bongard, J.T., Cain, T., Candela, D.M., Clay, C., Efe, B., Ji, Q.P., Klaus, E.M., Korner, A.P., Mitchell, K., Niemeyer, J.M., Rabinowitz, J.L., Ritter, S.P., Rojas, K., Sumrall, P., Market, P.S. and Lupo, A.R. (2020) Hurricane Florence Makes Landfall in the Southeast USA: Sensitive Dependence on Initial Conditions, Parameterizations, and Integrated Enstrophy. Atmospheric and Climate Sciences, 10, 101-124. https://doi.org/10.4236/acs.2020.102005

Received: October 12, 2019

Accepted: February 4, 2020

Published: February 7, 2020

Copyright $\odot 2020$ by author(s) and Scientific Research Publishing Inc. This work is licensed under the Creative Commons Attribution International License (CC BY 4.0).

http://creativecommons.org/licenses/by/4.0/

(c) (i) Open Access

\begin{abstract}
The overall purpose of this paper is to post-evaluate the predictability of Hurricane Florence using the Advanced Research Weather Research Forecast (WRF) (ARW) version of a mesoscale model. This was performed over the period from 0000 UTC 13 September 2018 through 0000 UTC 18 September 2018. The WRF ARW core resolution used here was the $27-\mathrm{km}$ grid spacing chosen to in order to balance finer resolution against in house processing time and storage. The large-scale analysis showed that a change in the Northern Hemisphere flow regime, especially the flow in the western part of the Northern Hemisphere may have contributed partly to the reduced forward speed of the tropical cyclone. In order to measure the predictability of a system, we will use different convective and boundary layer schemes initialized from the same conditions. The results demonstrated that the sign of the local IRE tendency was similar to that of the Northern Hemisphere Integrated Enstrophy. The results also showed that when the boundary layer, convective, and cloud microphysical schemes of the model were varied, the areal coverage of heavy precipitation of Florence was under-forecast by approximately $10 \%$ or more, and the heaviest amounts were under-forecast by an average of about $20 \%$.
\end{abstract}

\section{Keywords}

Predictability, Model Behavior, Integrated Entrophy, Precipitation, Tropical Cyclone 


\section{Introduction}

Hurricane Florence made landfall in the southeast United States during 14-17 September 2018 resulting in more than 15 deaths and causing over one billion dollars in damage [1]. The storm was associated with at least one report of more than $75 \mathrm{~cm}$ of rain over the four-day period, see the Community Collaborative Rain Hail and Snow network (CoCoRaHS- http://www.cocorahs.com/). Hurricane Florence began as a tropical depression over the eastern tropical Atlantic on 31 August 2018 [2]. By 11 September, Florence was classified as a major hurricane (category four) on the Saffir-Simpson Scale with maximum sustained winds of more than $70 \mathrm{~m} \cdot \mathrm{s}^{-1}(140 \mathrm{mph})$. However, the storm made landfall as a category one storm on 14 September after it was anticipated to make landfall as a major hurricane.

While the track of Florence was well-forecast by operational numerical models, the rapid loss in intensity as the storm approached the coast as well as the amount of rain produced by the storm was not well forecast. Hurricane track prediction has improved substantially in recent years, but models often fail to capture the intensity of very strong tropical cyclones [3]. They [3] demonstrated that the predictability of a rapidly developing tropical cyclone (Hurricane Patricia-October 2015) was associated with dynamics consistent with violent turbulence, or rough dependence on the initial conditions (RDIC) [4] [5]. Such conditions indicate that, in some cases, predictability of certain phenomena at some time scales is nearly impossible given our current understanding of fluid dynamics [6].

The quantity integrated enstrophy (IE) was first proposed by [7] and they demonstrated that in a barotropic atmosphere, IE is proportional to the system stability and predictability. Then, [8] showed that if a large region of the $\mathrm{NH}$ was used to calculate IE, the regional estimate and its change with time was similar to the hemispheric value. Recent studies [3] [9] [10] [11] used the quantity Integrated Regional Enstrophy (IRE) to examine predictability within mid-latitude events such as synoptic-scale cyclones and blocking events. The study of [9] examined the development of a cold-season mid-latitude cyclone over the southeast United States using two different models and varying the different boundary layer physics and convective precipitation parameterizations. They found that differences in forecasts using parameterization schemes within a model were smaller than those using two different models.

The work of [10] used IE to study the performance of the Global Ensemble Forecast System (GEFS) in simulating the dynamic behavior of two blocking events. They found that as expected, individual ensemble members performed better than the control or the ensemble mean, but that the IE was forecast reasonably. Then [11] demonstrated that the timing of onset and the location for blocking was forecast well by the GEFS ensemble mean fields. However, the block intensity was not forecasted well by the GEFS model. Additionally, the GEFS model could not sustain the blocking event for as long as they were ob- 
served to exist. The model had difficulty with the timing of block termination as well. Finally, [11] examined the relationship between block intensity and IRE during block onset. They found that the rate of precursor upstream rapid cyclogenesis was related to a peak in IRE near block onset followed by a peak in block intensity.

This study will investigate the ability of the in-house version of the Advanced Research Weather Research Forecast (WRF-ARW) model to represent the behavior of the large-scale conditions associated with the $\mathrm{NH}$ flow during the landfall of Hurricane Florence as well as the area and amount of the heaviest precipitation associated with the storm. This study will examine the dynamics of the large-scale NH flow at the time of landfall for Hurricane Florence in section three using teleconnection indexes and IRE as the diagnostics. It is postulated that changes in the hemispheric large-scale flow may have been partly responsible for the weakening and change in the forward motion of the storm. Additionally, the sensitivity of the IE diagnostic and precipitation character of Hurricane Florence to the WRF-ARW model parameterizations of convective and cloud microphysics schemes, as well as boundary layer schemes will be compared in section four. Section five will present the main conclusions.

\section{Data and Methodology}

\subsection{Data}

In this study, observational data were obtained from the National Centers for Environmental Prediction/National Center for Atmospheric Research (NCEP/NCAR) re-analyses. These data are archived at the NCAR research facilities in Boulder, $\mathrm{CO}$ [12] [13], which can be used to provide large-scale meteorological data at various resolutions from $1^{\circ} \times 1^{\circ}$ to $2.5^{\circ} \times 2.5^{\circ}$ latitude-longitude grids. The characteristics of Hurricane Florence were obtained from [2]. Finally, teleconnection index information was obtained from the National Oceanic and Atmospheric Administration (NOAA) Climate Prediction Center (CPC) teleconnections website (https://www.cpc.ncep.noaa.gov/products/precip/CWlink/). The daily Arctic Oscillation (AO), North Atlantic Oscillation (NAO), and Pacific North American (PNA) teleconnection indexes were examined here and are described more thoroughly in [14] or [15] and references therein.

The model used here was the Advanced Research WRF (WRF-ARW)Weather Research and Forecast model) which is available in-house at the University of Missouri Weather Analysis and Visualization (WAV) Laboratory. The initial conditions were obtained from the Global Forecast System (GFS) archived at the NCEP and available at

https://www.ncdc.noaa.gov/data-access/model-datasets/global-forecast-system-g fs. The GFS is a global numerical weather prediction model used at NCEP, which can be run four times a day and has the capability to forecast up to sixteen days in advance. It has various spectral resolutions on a hybrid coordinate system of sigma and pressure; its horizontal resolution is approximately up to 35 
$\mathrm{km}$ mesh and in the vertical, the domain ranges from $997.3 \mathrm{hPa}$ to $0.266 \mathrm{hPa}$ for a surface pressure of $1000 \mathrm{hPa}$ [16]. The model was run for 120-h with a resolution of $27 \mathrm{~km}$ over the bounded area $25^{\circ} \mathrm{N}$ to $45^{\circ} \mathrm{N}$ latitude and $95^{\circ} \mathrm{W}$ to $65^{\circ} \mathrm{W}$ longitude from 0000 UTC 13 September 2018 to 0000 UTC 18 September 2018. In order to produce an ensemble, the convective schemes and boundary layer schemes were varied here and these are described below.

\subsection{Methodology}

The work of [7] postulated that if the atmosphere is barotropic, the sum of the positive Lyapunov exponent(s) in the atmosphere can be expressed as the area of integrated enstrophy (IE). Then, [8] demonstrated that the IE summed over a large area of the mid-latitude Northern Hemisphere over time will correspond strongly to the hemispheric value, which they called IRE or Integrated Regional Enstrophy. This is expressed as;

$$
\operatorname{IRE}=\sum_{i>0} \lambda_{i} \approx \int_{A} \zeta^{2} \mathrm{~d} A
$$

where $\lambda_{i}$ is the ith Lyapunov exponent that is greater than zero in a dynamic system, $\zeta$ is the vorticity, or the curl of the wind vector, and the quantity squared is called enstrophy, which is the dissipation tendency of a fluid. A constant proportional to unity is implied by the very high correlation [3] [6]. Also, [8] demonstrated the utility of IRE in identifying the onset and termination of atmospheric blocking, while [10] showed that this quantity could be used to study blocking dynamics. Additionally, [10] and [17] used this quantity to study flow regime transition. In (1), the vorticity is calculated via the geostrophic relationship using second-order finite differencing and IRE is calculated within the region defined above.

\subsection{Methodology}

In this study, a pseudo ensemble was produced in house by running the WRF-ARW model using several different convective, cloud microphysics, and boundary layer schemes from the same initial state. The initial state was chosen was 0000 UTC 13 September 2018 as the tropical cyclone was weakening and had begun to slow its forward motion. This was also the first time that the storm was in the research domain chosen for heavy precipitation studies in the southeast USA by the University of Missouri synoptic scale dynamics group. For the control simulation schemes WRF Single Moment 6-class was used for cloud microphysics, the Tiedke scheme for cumulus parameterization, the RRTMG for long and shortwave radiation parameterization, the Mellor-Yamada-Janjic (YMJ) for boundary layer parameterization, the Unified Noah for clay surface parameterization, and Eta Similarity for surface physics parameterization. Changes were made to one parameterization at a time to identify changes to the simulations and were analyzed as in the following text below.

The Grell-Freitas convective (GFC) scheme features a scaling and aerosol-aware approach to convective parameterization and features a tri-modal ap- 
proach to handling convection, which matches the types of convection present in tropical systems [18]. This scheme is utilized seldom in recent tropical cyclone sensitivity studies in spite of being used heavily to study other tropical phenomena [19]. Previous studies have shown that cumulus physics schemes are more likely to affect intensity than storm track [20] [21]. However, given the unique track of Florence, the track produced by the GFC scheme was of interest as well. Because of the relatively new improvements made to this scheme, which includes the handling of mid-level convection and adjustments to rainfall estimation [22], it would be useful to know how well it predicts intensity and track adjustments as well as the predictability accuracy in comparison to other physics schemes.

The Betts Miller convective (BMC) scheme is a convective adjustment scheme, which includes both deep and shallow convection [23]. For deep convection, this scheme uses quasi-equilibrium thermodynamic profiles as a reference whose shape is based on observations [23]. The work of [24] made appropriate adjustments to the BMC (now BMJC) scheme to add the cloud efficiency to reduce the excessive precipitation [23].

The BMJC scheme strengths are its ability to operate well in moist environments without a capping inversion. It includes complicated features but does not require much computing resources making it ideal for use in house. The BMJC scheme demonstrated lower bias in precipitation over land and over the Gulf of Mexico region when combined with WRF single moment microphysics class5 (WSM5) microphysics option. The BMJC also provided better hurricane track forecasts with the Kessler (KESS) [25] [26] or the microphysics [27], compared with other schemes such as the Kain and Fritsch convective (KFC), no cumulus parameterization (NCP), and Grell-Devenyi (GD) [28] [29]. The BMJC scheme, however, produces more precipitation than Kain-Fritsch convective (KFC) scheme in the simulations of Hurricane Ivan [30]. The BMJC and KFC schemes both gave a clear representation of the intense structure of Tropical Cyclone Nargis, but the KFC scheme produced a realistic intensity of the storm [31]. This scheme generally deals with convection better than other cumulus parameterization schemes, thus, this scheme was chosen for this study.

The KFC parameterization scheme was chosen for use here in spite of the fact is not currently integrated into most tropical cyclone numerical modelling studies. However, it has been used in the past for studies since it does handle convection reasonably well both across the tropics and the mid-latitudes [28] [32]. A key reason why the KFC was chosen was because the mass-flux scheme that is embedded within this scheme handles convection in such a way that it accommodates both entrainment and detrainment for both updrafts and downdrafts, respectively [33]. This is particularly important for tropical cyclone simulations since spiral banding features within hurricanes have corresponding regions of updrafts and downdrafts associated with the inner and outer parts of the warm-core low. In addition, the KFC handles convective updraft generation such that these updrafts remove higher theta-e values from the lower tropos- 
phere and transport it aloft, a key component of energy transfer within the eyewall and inner core of a tropical cyclone [34]. The parameterization of moist downdrafts that is included in the KFC scheme, especially for stronger downdrafts, reduces compensatory subsidence and consequently generates more realistic convective warming and drying tendencies at the lower part of the convective boundary layer. Furthermore, the KFC has been designed for models with 20 to $50 \mathrm{~km}$ spatial resolution, making it a viable candidate for use here [32]. Additionally, the scheme also allows for the development of an effective secondary circulation that often generates a numerically modelled environment, which is more conducive for generating more intense warm-core low-pressure systems. This would be helpful for modelling features within an intense tropical cyclone such as (but certainly not limited to) the eye, eye-wall, a moat when and if one was present, spiral convective bands, and other features.

Numerical weather prediction models are known to have difficulty predicting precipitation. One of the reasons for this is the lack of a realistic depiction for clouds in these models. It is for this reason that integrating schemes that address the issue of cloud and precipitation forecasting is crucial. One such scheme would be the Ferrier scheme that has been included in the Eta scheme. The Ferrier (FER) scheme is ideal for use when looking at moisture transport and forecasting precipitation. This scheme has a vertical resolution of 38 layers and a horizontal resolution at $40 \mathrm{~km}$. The FER scheme addresses the issue of forecasting clouds and precipitation by using separate schemes for clouds and precipitation within the code. For the cloud scheme, the primary feature is the calculation of cloud water and cloud ice, since the cloud water/ice mixing ratio is a key variable in the cloud formation. By including cloud ice as well as the horizontal advection of clouds, a large improvement on cloud precipitation and relative humidity is achieved. After calculating the cloud water/ice mixing ratio, the FER is used for the diagnostic calculation of precipitation. Few schemes or models have a specific approach for calculating precipitation directly, rather they get precipitation outcomes as a result of calculating a different parameter, this is one of the reasons the FER scheme is so useful. The precipitation parameterization accounts for two important features. The first being the gradual melting of snow in warm cloud regions allowing for snow and rain to coexist, and the second being it takes into account evaporation from precipitation.

There are many reasons for using the FER scheme to analyze the moisture transport associated with hurricane Florence. The first reason is that this scheme addresses the issue of excessive condensation of moisture over oceans. In order to account for this, the critical value of relative humidity is set as a constant. Six different precipitation processes are accounted for also in the scheme. These processes are observed in clouds to produce a more accurate precipitation forecast. They include, auto conversion of cloud water to rain, collection of cloud droplets by the falling rain drops, auto conversion of ice particles to snow, melting of snow below the freezing level and the evaporation of precipitation below 
cloud bases. The FER scheme also explicitly defines cloud levels, with the low cloud layer being from the surface to $640 \mathrm{hPa}$, the mid-level from $640-350 \mathrm{hPa}$ and the high level from $350 \mathrm{hPa}$ to the top of the model. The cloud scheme has improved forecasts for precipitation at all thresholds and is most apparent at levels below $850 \mathrm{hPa}$ and above $550 \mathrm{hPa}$ (e.g. [28]).

The WDM6 scheme is a double moment, bulk microphysical scheme that predicts the mixing ratio of water vapor, cloud droplets, cloud ice, snow, rain, and graupel along with the concentrations for rain and cloud water (e.g. [35]). Single moment schemes predict only the mixing ratios. As such, this scheme is ideal for predicting the number concentration of cloud and rainwater. The double-moment approach allows for an evolving mean diameter, leading to a more efficient simulation of microphysical processes. Additionally, this scheme includes prognostic equations that allow for investigating aerosol effects on clouds and precipitation process. Simulations of the WDM6 can be run at different resolutions. Coarse resolution simulations will not resolve supersaturation in one grid box, thus, higher resolution simulations should be employed if this variable is desired. A bulk microphysical parameterization is computationally efficient compared to a bin-resolving method. Single moment bulk schemes predict only the mixing ratios of hydrometeors using a distribution function for the hydrometeor size. A double-moment scheme has the advantage of, not only predicting the mixing ratio, but also the number concentration of hydrometeors. A double moment approach allows more size flexibility and the diameter of the hydrometeor can evolve improving the single moment approach. Double moment schemes require more computational time but have been shown to simulate precipitating convective clouds more accurately. Double-moment schemes rely on the accuracy of several microphysical processes. The WDM6 scheme predicts the concentration of cloud and rainwater with the CCN. The six water species types that the WDM6 predicts mixing ratios for are water vapor, cloud droplets, cloud ice, snow, rain, and graupel.

The WDM6 scheme was chosen because of its computational efficiency and its ability to simulate precipitation convective clouds compared to a single moment scheme. In the control run of the experiment the CONUS physics suite was used, since the focus of the experiment is the land-falling period of the hurricane. The CONUS physics suite uses the WRF Single moment 6 class Scheme (WSM6). In an attempt to improve the rainfall prediction, the WDM6 scheme was tested as a comparison to the control. Features of the WDM6 scheme include the ability to be used in warm rain processes, and the prediction of $\mathrm{CCN}$, and the number concentrations of cloud and rain. Studies indicate that the rain number concentration is important in determining the precipitation rate and storm morphology because of the regulation of other microphysical processes particularly the evaporation rate. The study of [36] found that increased rain-drop concentrations in double moment schemes result in more evaporation in the stratiform region of the storm and lead to lower rainfall rates. In general 
[36] found that light precipitation activity is reduced compared to the WSM6 while moderate and heavy precipitation increases. However, a high-CCN condition can suppress conversion from cloud droplet to raindrops and decrease precipitation.

When forecasting weather phenomena, it is important to look at the physical processes within the planetary boundary layer (PBL) with the most important process being buoyancy. Buoyancy describes the thermodynamic and kinematic profiles that models incorporate in their forecasts. These processes continue to be poorly represented in the PBL, so forecasters use many different schemes to help combat this problem. One of these schemes is the Yonsei University (YSU) Scheme. This is an extension of the previous Medium Range Forecast (MRF) model PBL scheme (e.g., [37]) and uses the MM5 similarity theory. This scheme focuses on buoyancy transport and is a powerful scheme that many modelers can use to help better forecast. According to [38], the YSU is the first and most widely used PBL scheme.

The YSU scheme was selected primarily because of its ability to accurately portray buoyancy transport and boundary layer depth, as compared to other PBL schemes. Then, [39] has shown that the YSU scheme accurately depicts the depth of the PBL. The boundary layer height is calculated by using the bulk Richardson number method. A major advantage is that the YSU scheme represents entrainment at the top of the PBL explicitly. Previous studies, particularly with Hurricane Isabel, have shown radial winds to be consistent with observed data and the slope of the eyewall to be well predicted [37]. Furthermore, YSU tends to have a less cold and moist bias than other schemes. Since it is a non-local closure scheme, it is able to incorporate all interactions between the atmospheric quantities within all the layers of the PBL, meaning that vertical mixing from the entire depth of the PBL is considered.

The University of Washington (TKE) is a planetary boundary layer scheme specifically developed for use in a subtropical marine environment [40]. This model is based on a 1.5-order turbulent closure scheme and the [41] formulation. This boundary layer model was revised by [42] to include a new parameterization for shallow convection in cloud-topped boundary layers. The model was revised again by [43] to improve the treatment of moist turbulence in cumulus updrafts. This scheme was chosen since Hurricane Florence was located over the ocean at the time of the initial conditions.

\section{Large-Scale Analysis}

Hurricane Florence began as a tropical wave (Figure 1) near the coast of Africa on $30-31$ August 2018 at approximately $13^{\circ} \mathrm{N}$ and $20^{\circ} \mathrm{W}$. The disturbance strengthened into a tropical depression and a tropical storm by 1 September 2018. Thus, this tropical cyclone would be considered an Eastern Atlantic or more colloquially a "Cape Verde Storm". Florence moved northwestward and became a major hurricane (Category 3 on the Saffir Simpson Scale) on the 5 


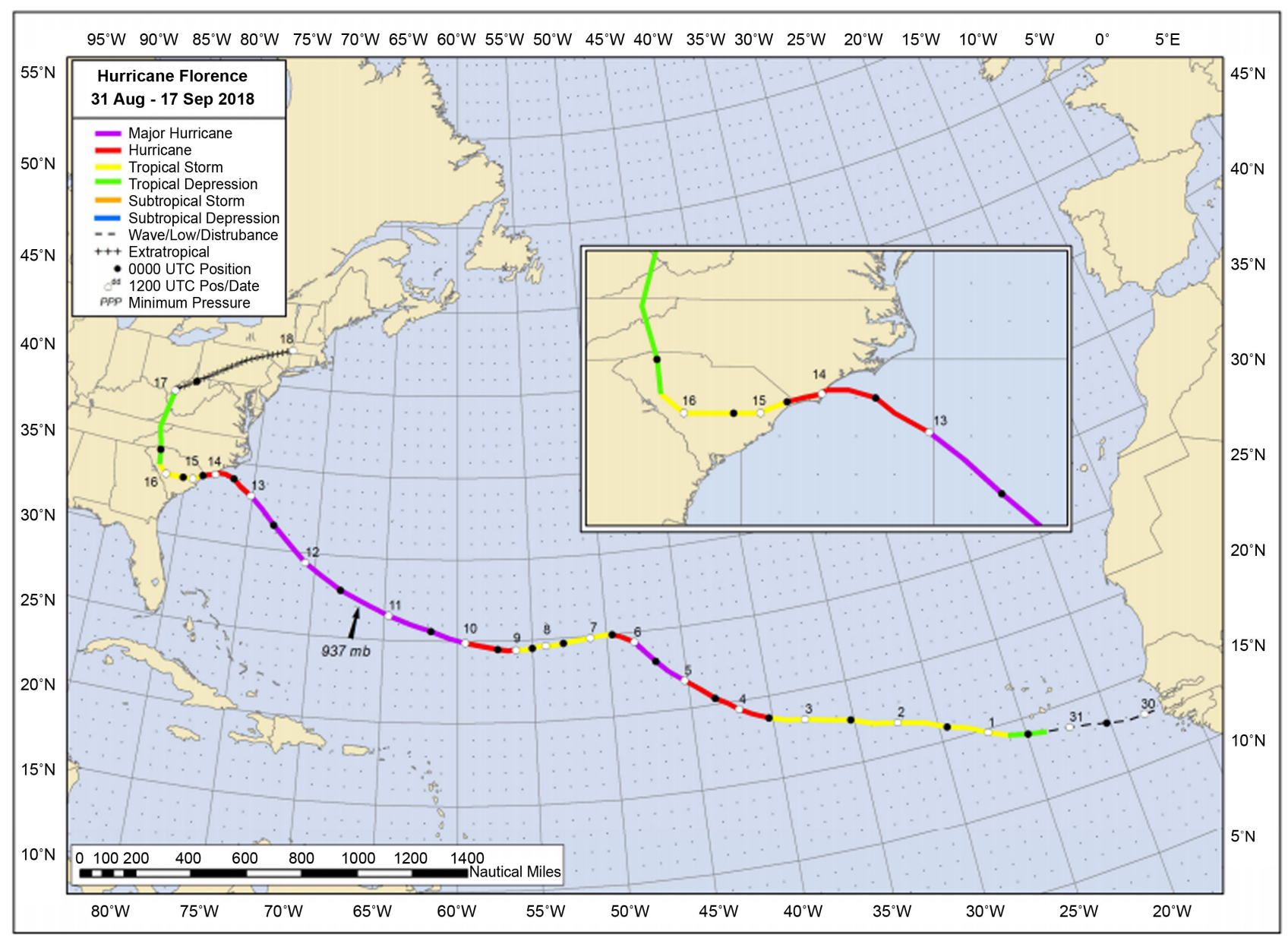

Figure 1. Best track information for Hurricane Florence 31 August-17 September 2018 (obtained from NHC, 2018).

September around $22^{\circ} \mathrm{N}$ and $45^{\circ} \mathrm{W}$. During this time, the $500 \mathrm{hPa}$ NH flow became less zonal (Figure 2), and this is supported by a decrease in the AO Index (Table 1). Also, both the NAO and PNA indexes show that a change in flow regime was occurring during this time. The $500 \mathrm{hPa}$ height anomalies (Figure 2) showed an amplified wavelike pattern across the Pacific, North America, and Atlantic at the start of September and by 7 September the flow pattern was weaker and less organized across the region. Examining the observed IRE and its time derivative (DIRE [10]) for September 2018 (Figure 3) suggests that IRE peaked at or around 3 September 2018 signaling a change in the NH flow regime adding further support for the analysis here. Additionally, the $500 \mathrm{hPa}$ maps suggest that the subtropical Atlantic was dominated by anti-cyclonic flow which would steer Florence westward.

During 6 September, Florence weakened to a tropical storm and began to take a more westerly track (Figure 1). Then, the storm intensified after 9 September culminating in a maximum intensity of a Category 4 storm with wind speeds at $70 \mathrm{~m} \cdot \mathrm{s}^{-1}$ on 12 September. During this time, the tropical cyclone turned to move northwestward again toward the Carolinas in the USA. As the storm made landfall on 14 September, the forward speed slowed considerably and the storm had 

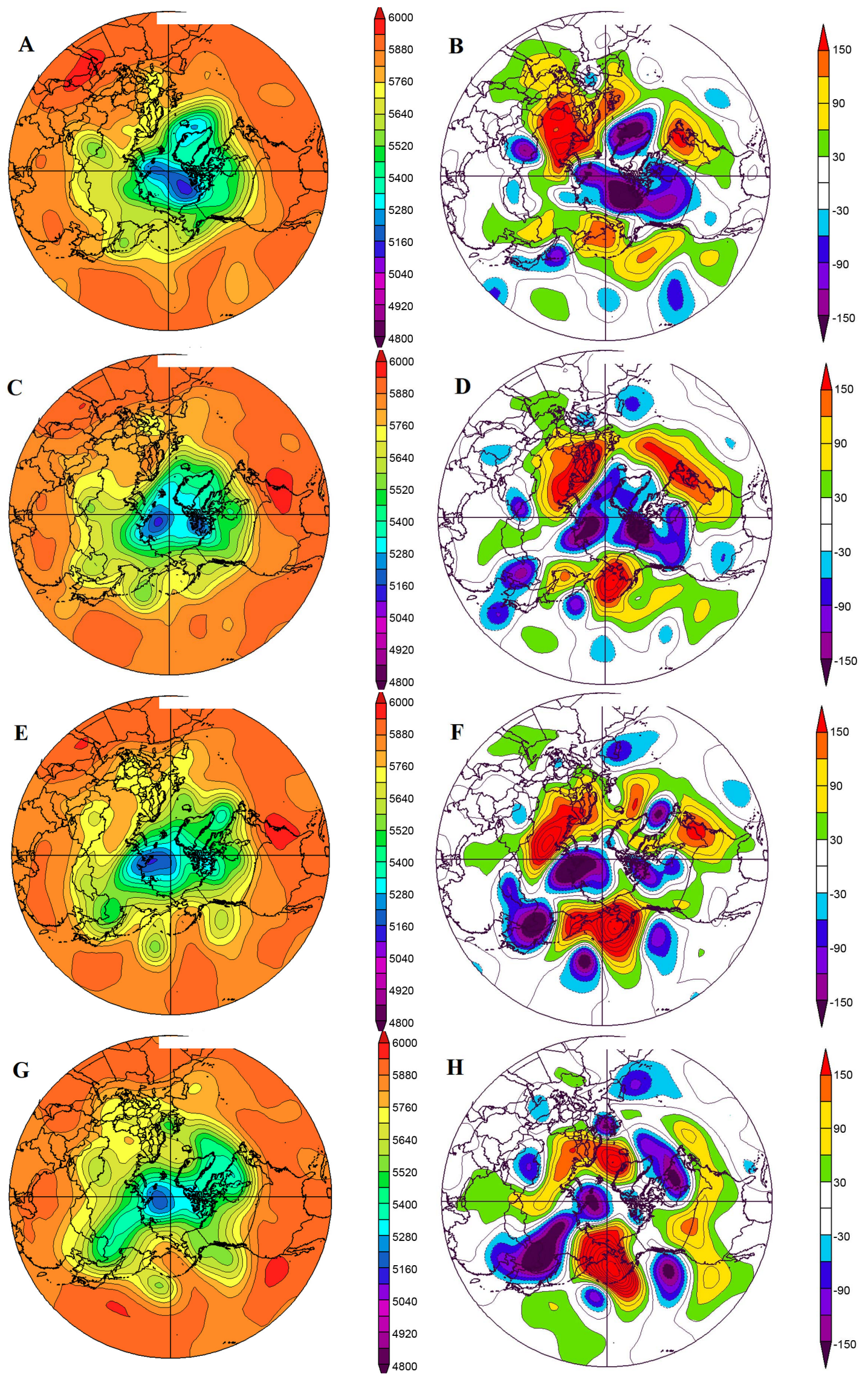

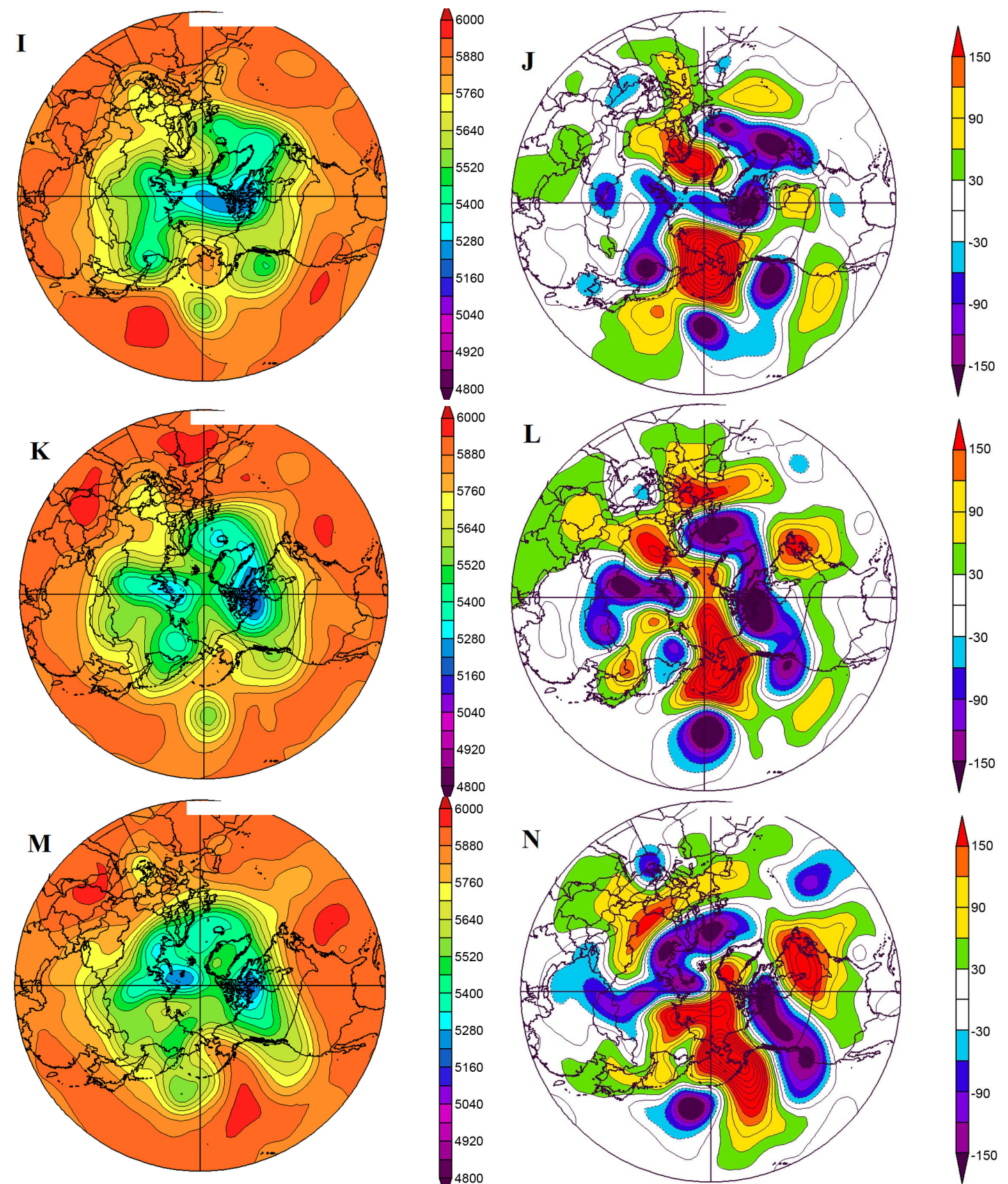

6000
5880
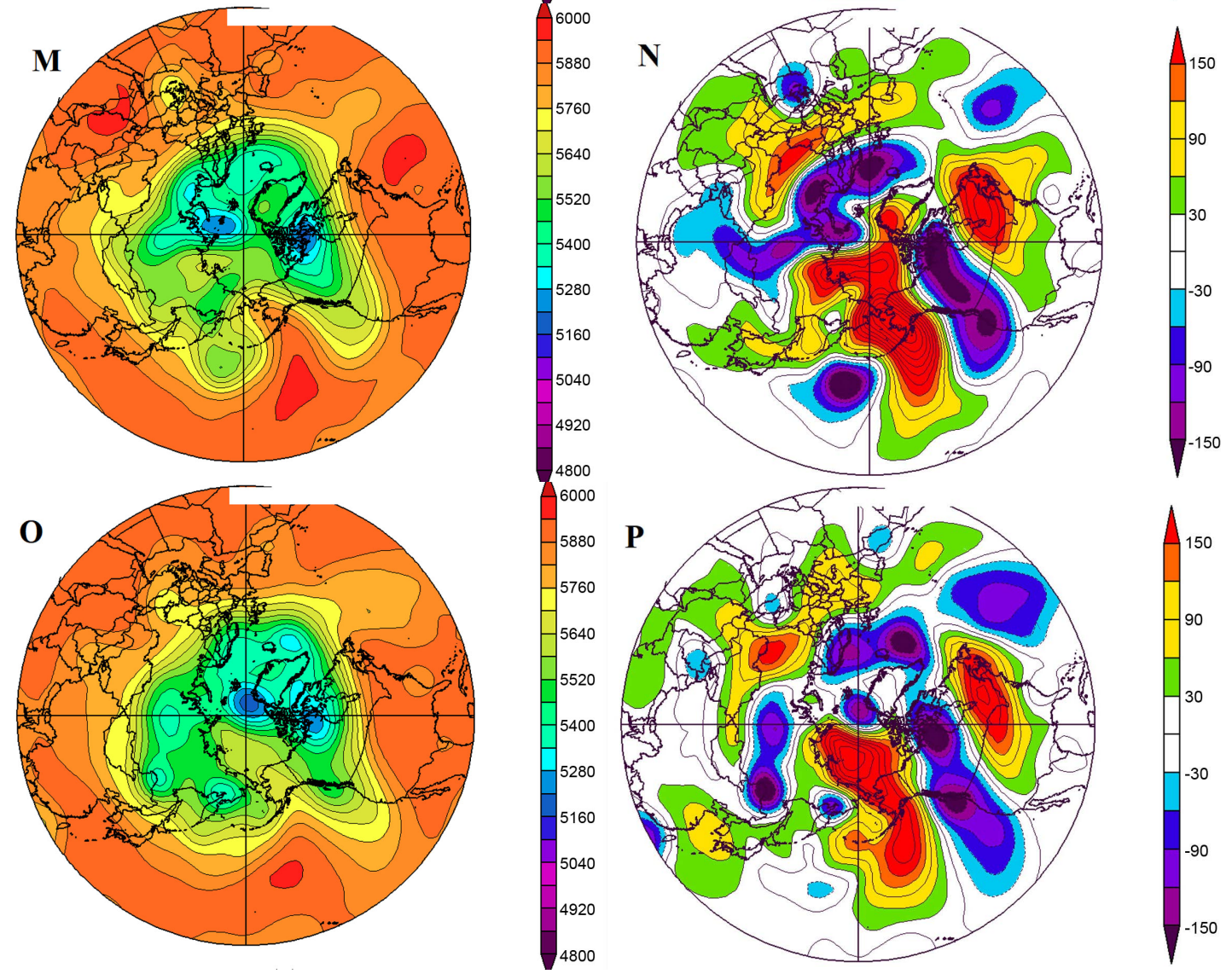

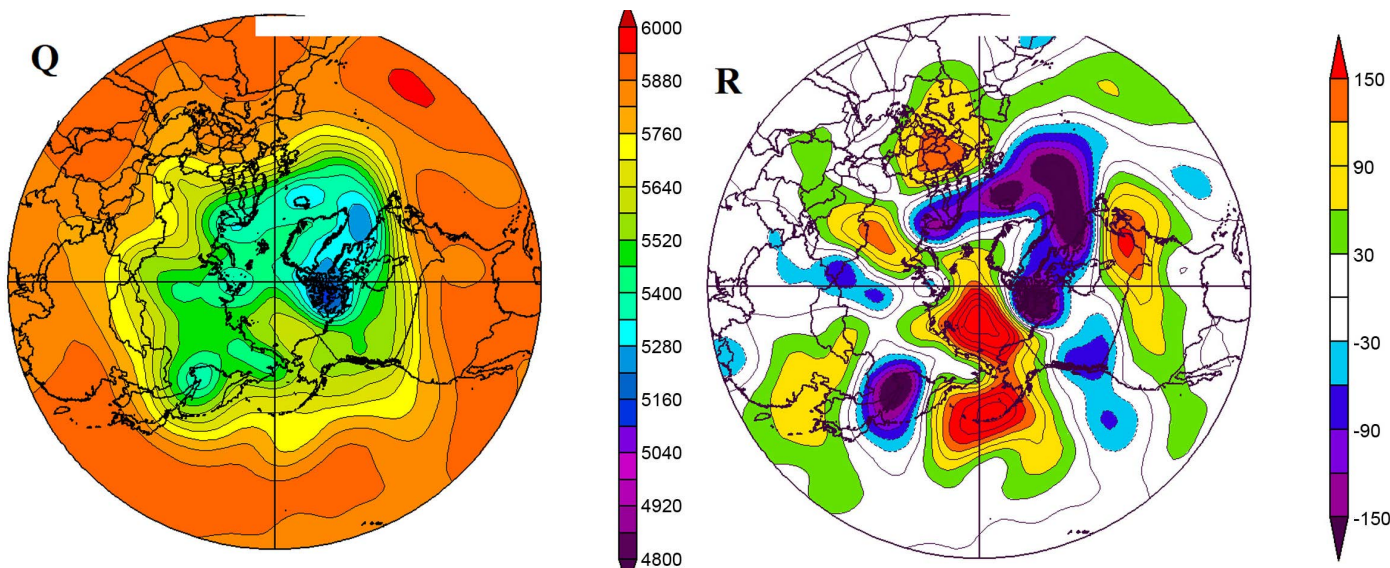

Figure 2. The NH $500 \mathrm{hPa}(\mathrm{a}),(\mathrm{c}),(\mathrm{e}),(\mathrm{g}),(\mathrm{i}),(\mathrm{k}),(\mathrm{m})$ (o), and (q) height (m) and (b), (d), (f), (h), (j), (l), (n), (p), (r) height anomalies (m) for 1 Sept, 3 Sept, 5 Sept, 7 Sept, 9 Sept, 11 Sept, 13 Sept, 15 Sept, and 17 Sept 2018, respectively. The height and height anomalies are contoured every 60 and $30 \mathrm{~m}$, respectively.

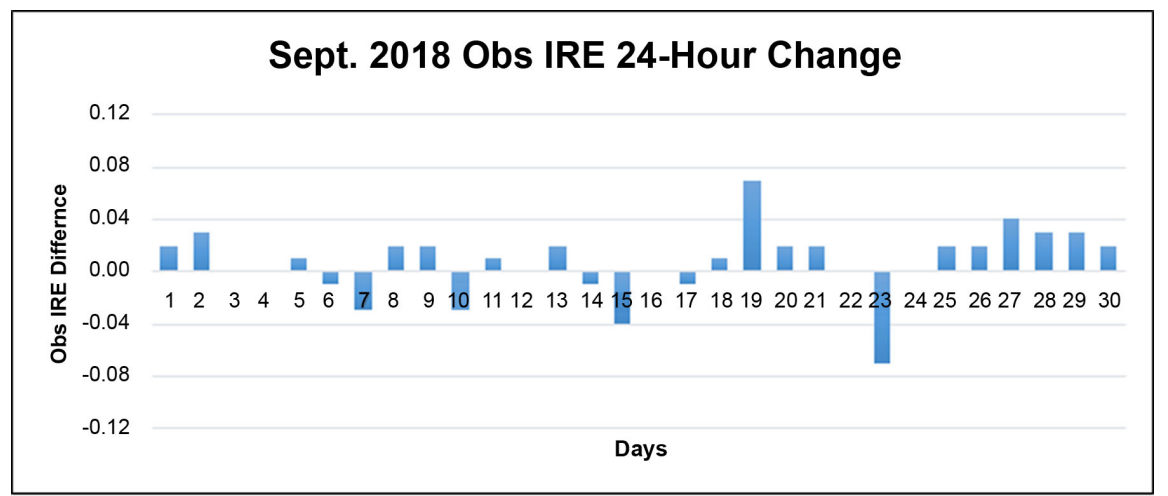

Figure 3. The $24 \mathrm{hr}$ difference in observed IRE integrated over the $\mathrm{NH}$ during September 2018. This value was calculated by taking the current day minus the previous day.

Table 1. The major teleconnection indexes for the month of September 2018.

\begin{tabular}{cccc}
\hline Date & AO & NAO & PNA \\
\hline 192018 & 1.307 & 0.703 & -0.943 \\
292018 & 0.817 & 0.802 & -0.328 \\
392018 & 0.739 & 0.771 & -0.155 \\
492018 & 0.097 & 0.266 & -0.009 \\
592018 & -0.534 & -0.004 & 0.069 \\
692018 & -0.449 & 0.188 & 0.172 \\
792018 & -0.395 & 0.218 & 0.492 \\
892018 & -0.222 & 0.393 & 0.667 \\
992018 & -0.119 & 0.723 & 0.492 \\
1092018 & 0.275 & 0.996 & 0.668 \\
1192018 & 0.717 & 1.006 & 1.382 \\
1292018 & 0.996 & 0.597 & 1.802 \\
1392018 & 0.651 & 0.447 & 1.968 \\
\hline
\end{tabular}




\begin{tabular}{|c|c|c|c|}
\hline Continued & & & \\
\hline 1492018 & 0.124 & 0.755 & 1.961 \\
\hline 1592018 & -0.082 & 1.245 & 1.742 \\
\hline 1692018 & 0.042 & 1.361 & 1.608 \\
\hline 1792018 & 0.260 & 1.131 & 1.600 \\
\hline 1892018 & 0.122 & 0.641 & 1.593 \\
\hline 1992018 & 0.339 & 0.256 & 1.274 \\
\hline 2092018 & 0.671 & 0.257 & 0.864 \\
\hline 2192018 & 0.601 & 0.219 & 0.514 \\
\hline 2292018 & 0.951 & 0.391 & -0.284 \\
\hline 2392018 & 1.528 & 0.568 & -1.032 \\
\hline 2492018 & 1.941 & 0.886 & -1.262 \\
\hline 2592018 & 2.265 & 1.071 & -1.025 \\
\hline 2692018 & 2.130 & 1.292 & -0.313 \\
\hline 2792018 & 1.482 & 1.396 & 0.492 \\
\hline 2892018 & 0.885 & 1.735 & 1.219 \\
\hline 2992018 & -0.061 & 1.370 & 2.067 \\
\hline 3092018 & -0.168 & 1.354 & 2.197 \\
\hline
\end{tabular}

weakened into a Category 1 tropical cyclone. For the next $72 \mathrm{~h}$ (Figure 1), the storm moved very slowly from the Carolinas to Southern Ohio bringing heavy rain and widespread flooding with it.

The $500 \mathrm{hPa}$ flow became more meridional by 5 September (Figure 2) and during the next 10 days a strong ridge became a moderate intensity and short lived blocking event in the Gulf of Alaska from 7-13 September 2018 (http://weather.missouri.edu/gcc). From 7 to 11 September, the $500 \mathrm{hPa}$ height anomaly pattern over North America showed a reversal from a stronger negative to a moderate positive anomaly. After 11 September (Figure 2), the same 500 $\mathrm{hPa}$ height anomaly pattern that existed at the start of the month re-established itself and the flow was more zonal again by 15 September with the jet stream aligned from southwest to northeast over the USA. Thus, Florence was located on the equatorward side of this jet maximum underneath anticyclonic flow. This may have contributed to the slower forward motion for the $72 \mathrm{~h}$ period from 14-17 September. Table 1 shows that the NAO and AO both reached minimum values on 5 September and began to increase, reaching local maxima on 11 and 12 September 2018, respectively. Both indexes reached another local maximum on 16 and 17 September 2018. The NH IRE began to increase again generally from 8-13 September (Figure 3) and then after 13 September decreases indicating a local maximum on that date. This change possibly signaled the end of the meridional NH flow regime. The IRE would generally decrease again until another strong increase occurred on 18 and 19 September 2018. 
In summary, the first half of September featured anticyclonic conditions over the subtropical North Atlantic (Figure 2), which likely contributed to steering Florence westward. Further support can be garnered by examining the steering level winds (not shown) over the Atlantic for all the times corresponding to Figure 2. Figure 4 shows the mean $700 \mathrm{hPa}$ vector winds for the first part of September 2018. The flow is easterly generally over the subtropics where Florence tracked. The steering of Atlantic region tropical cyclones by subtropical high pressure is well known [44] The teleconnection indexes and the IRE suggested the $500 \mathrm{hPa} \mathrm{NH}$ flow regime changed during the first five days to become meridional. This was accompanied by the weakening and disruption of a wave-like $500 \mathrm{hPa}$ height anomaly pattern that was over the Pacific, North America, and extending over the Atlantic regions at the start of September. A moderate intensity short-lived block occurred over the east Pacific from 7-13 September 2018. The $500 \mathrm{hPa}$ height anomaly pattern described above for early September re-established itself after 11 September and the $500 \mathrm{hPa}$ flow was more zonal again by 15 September. Florence slowed after 14 September as it approached land and remained on the anticyclonic side of a southwest-northeast oriented jet stream over the USA. These two factors may explain the slowed forward motion of Florence as it weakened for $72 \mathrm{~h}$ before eventually being absorbed and carried by the jet stream over the northeast USA and out over the Atlantic. The forecast of Florence as it made landfall using the WRF-ARW model discussed in the next section will begin from 13 September 2018 covering the period of $\mathrm{NH}$ decreasing IRE, slowed forward motion, weakening, and heavy rainfall over the Carolinas.

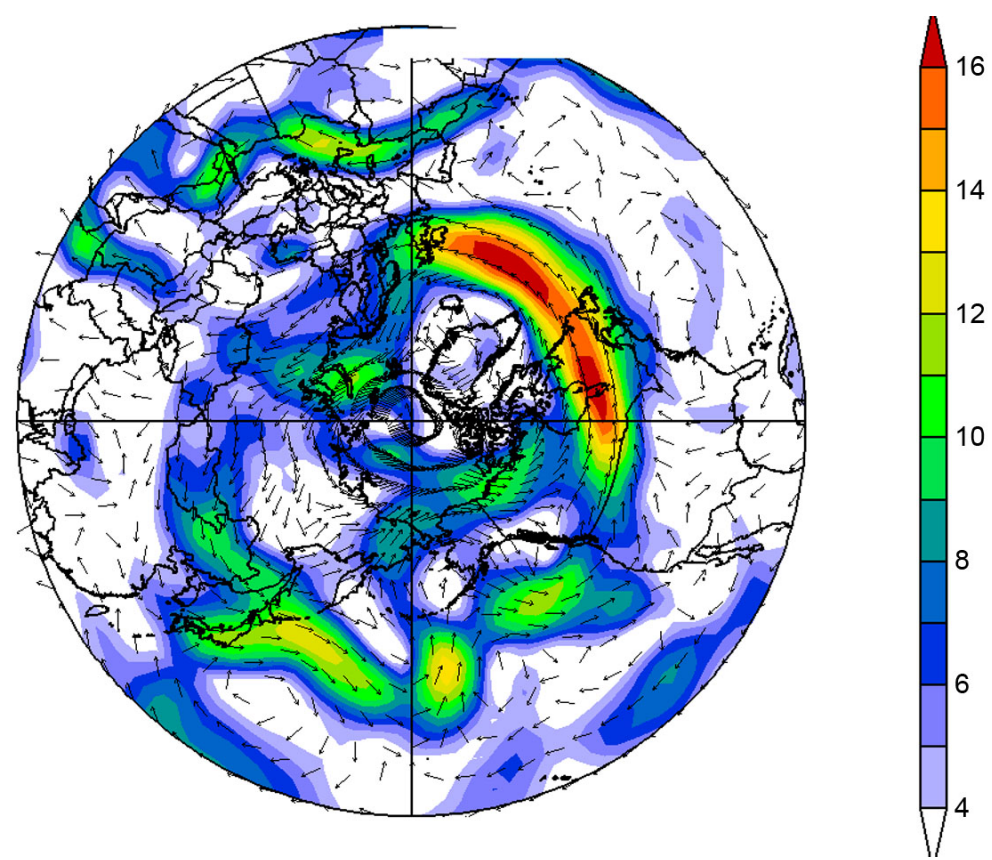

Figure 4. The mean Northern Hemisphere $700 \mathrm{hPa}$ vector winds $\left(\mathrm{m} \cdot \mathrm{s}^{-1}\right)$ for $1-15 \mathrm{Sep}$ tember 2018. 


\section{Predictability during Landfall}

Table 2 shows the change in IRE over the WRF domain from the initial time 1200 UTC 13 September 2018 for a $120 \mathrm{~h}$ period every 24-h. A comparison to Figure 3 shows that the IRE within the WRF domain was forecast well when comparing to the IE over the entire $\mathrm{NH}$. In general, the $\mathrm{NH}$ values were decreasing until 17 September and increased for the last $24 \mathrm{~h}$ period. The $24-\mathrm{h}$ model control forecasts were of the same sign for all but the last $24 \mathrm{~h}$ period. There was relatively little change (small increase) in NH IE and control model domain IRE from $48 \mathrm{~h}$ to $72 \mathrm{~h}$, while the ensemble members forecast a modest decrease. However, in summary, the control model and the ensemble members forecast IRE were generally consistent with each other and overall followed the change in NH IE. This latter finding is consistent with the results of Athar and Lupo (2010) described above. This result implied that local predictability was increasing as Florence slowed and moved inland. Examining individual members (Table 2), the 24-h IRE tendencies in the WRF-ARW runs using the YSU (0.04) and WDM6 (0.08) boundary layer schemes were closest to the control run. These two schemes produced root-mean-square (RMS) values (0.04 and 0.08 , respectively). The YSU RMS was the only run that was better than the ensemble mean. Additionally, the FER microphysics (0.14) and GFC convective schemes (0.18) produced RMS values that were superior to the remaining members.

Examining the pattern and rainfall amounts from each scheme also was performed. Figure 5 shows the WRF control simulation results for the heaviest 120 -h precipitation $(>300 \mathrm{~mm}$ ) totals. Much of North Carolina and part of the South Carolina border regions were modeled to receive more than $100 \mathrm{~mm}$ of

Table 2. The IRE values $\left(\times 10^{-6} \mathrm{~s}^{-2}\right)$ over the domain as simulated by the WRF-ARW model. The initial time is 1200 UTC 13 September 2018. The schemes are abbreviated as in section two. The model mean is last row and the percent change from 24 -h previous appears in each forecast column.

\begin{tabular}{ccccccc}
\hline Forecast h & 00 Init & $24 \mathrm{~h}$ & $48 \mathrm{~h}$ & $72 \mathrm{~h}$ & $96 \mathrm{~h}$ & $120 \mathrm{~h}$ \\
\hline Scheme & & & & & & \\
Control & 2.96 & $2.48 /-16.2$ & $1.84 /-25.8$ & $1.87 /+1.6$ & $1.38 /-26.2$ & $1.31 /-5.1$ \\
BMJC & 2.96 & $2.61 /-11.8$ & $2.27 /-13.0$ & $1.97 /-13.2$ & $1.56 /-20.8$ & $1.54 /-1.3$ \\
FER & 2.96 & $2.20 /-25.7$ & $1.77 /-19.6$ & $1.62 /-8.5$ & $1.33 /-17.9$ & $1.26 /-5.3$ \\
GFC & 2.96 & $2.92 /-1.4$ & $2.05 /-29.8$ & $1.74 /-15.1$ & $1.26 /-27.6$ & $1.33 /+5.6$ \\
KESS & 2.96 & $2.16 /-27.1$ & $1.86 /-13.9$ & $1.79 /-4.8$ & $1.65 /-7.8$ & $1.94 /+17.6$ \\
KFC & 2.96 & $2.82 /-4.8$ & $2.25 /-20.2$ & $2.15 /-4.4$ & $1.38 /-35.9$ & $1.41 /+2.2$ \\
TKE & 2.96 & $3.14 /+6.1$ & $2.35 /-25.2$ & $1.97 /-16.2$ & $1.41 /-28.4$ & $1.36 /-3.6$ \\
WDM6 & 2.96 & $2.54 /-14.2$ & $1.82 /-28.3$ & $1.72 /-5.5$ & $1.28 /-25.6$ & $1.22 /-4.7$ \\
YSU & 2.96 & $2.46 /-16.9$ & $1.85 /-24.8$ & $1.81 /-2.2$ & $1.31 /-27.7$ & $1.27 /-3.1$ \\
Ensemble & 2.96 & $2.59 /-12.5$ & $2.01 /-22.4$ & $1.85 /-8.0$ & $1.40 /-24.3$ & $1.40 / 0.0$ \\
\hline
\end{tabular}




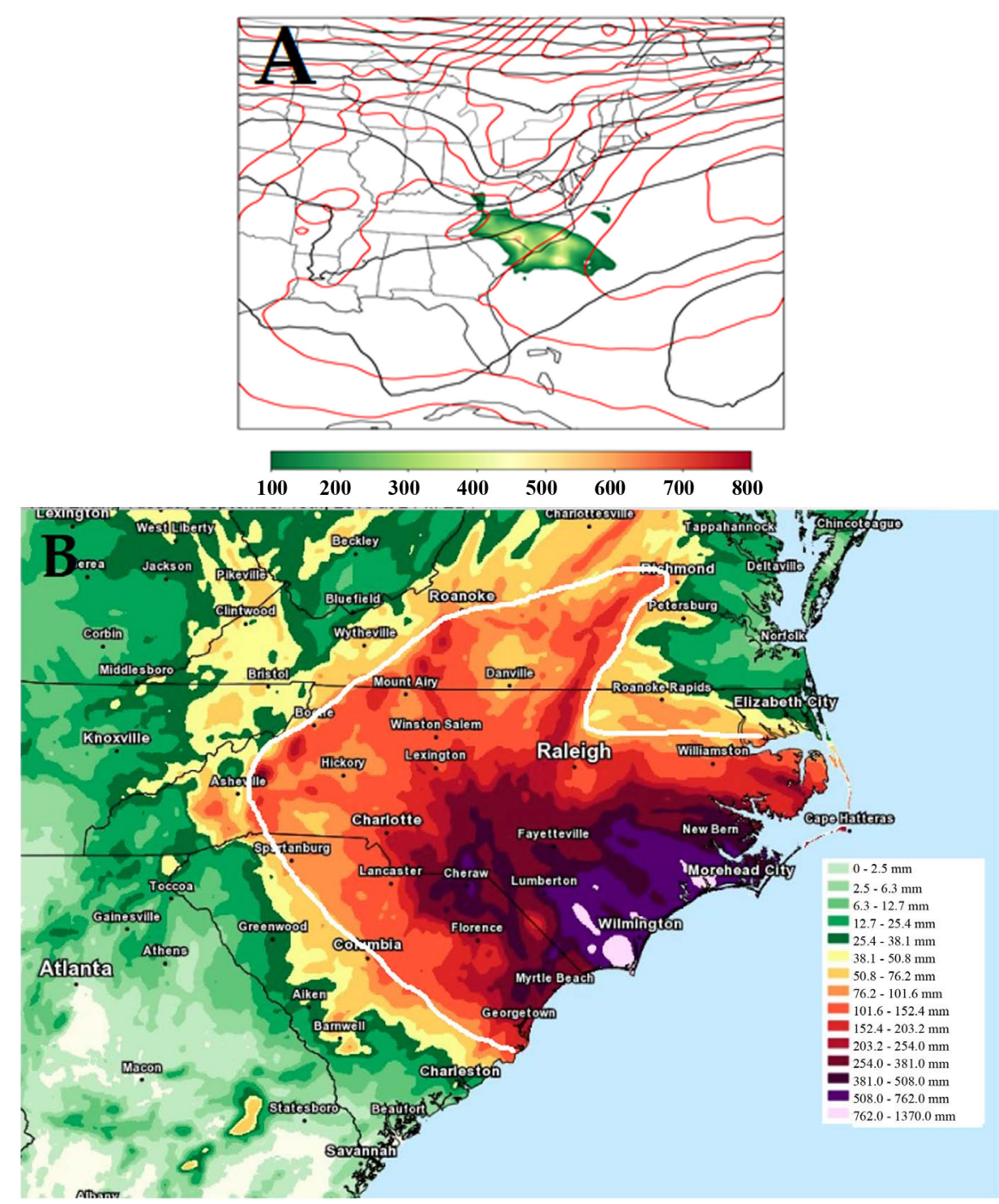

Figure 5. The (a) WRF control forecast and (b) observed precipitation totals (mm) for Florence from 0000 UTC 13 September - 0000 UTC 18 September 2018. The observed precipitation totals map can be found at the Wilmington, NC (ILM) Weather Forecast Office (WFO) website (https://www.weather.gov/ilm/HurricaneFlorence). In (a) values larger than $100 \mathrm{~mm}$ are shown beginning with the green shading, and in (b) the white line is the approximate location of $100 \mathrm{~mm}$ or greater observed totals. In (a) the black (red) countours are $500 \mathrm{hPa}$ height (sea level pressure).

precipitation (about $114,000 \mathrm{~km}^{2}$ ) with isolated values up to $650 \mathrm{~mm}$ along the border region (Table 3). The observed precipitation totals (Figure 5(b)) show that the WRF control model under-forecast the heaviest precipitation total amounts, but the general pattern of the heaviest amounts (areal coverage) was over-forecast in that the highest totals were found further inland in North Carolina and along the North Carolina-South Carolina state border. The heaviest observed precipitation amounts exceeded $750 \mathrm{~mm}$ with the greatest amount at $912.6 \mathrm{~mm}$, while the areal coverage of amounts greater than $100 \mathrm{~mm}$ was approximately $149,000 \mathrm{~km}^{2}$ (Table 3 ). The areal coverage of precipitation was estimated by fitting a box to the precipitation area on a scaled map. 
Table 3. The total precipitation amount $(\mathrm{mm})$ and approximate areal coverage $(\times 1000$ $\mathrm{km}^{2}$ ) for the observed and modelled maximum precipitation amounts over the domain as simulated by the WRF-ARW model.

\begin{tabular}{ccccc}
\hline Forecast & Amount $(\mathrm{mm})$ & Percent Different & Area Coverage & Percent Difference \\
\hline Observed & 912.6 & N/A & 148.74 & N/A \\
Control & 650.0 & -28.8 & 114.11 & -23.3 \\
BMJC & 750.0 & -17.8 & 113.54 & -23.7 \\
FER & 500.0 & -45.3 & 153.11 & +2.9 \\
GFC & 900.0 & -1.4 & 119.85 & -19.4 \\
KFC & 900.0 & -1.4 & 113.54 & -23.7 \\
TKE & 700.0 & -23.3 & 148.87 & +0.9 \\
WDM6 & 550.0 & -39.7 & 139.92 & -5.9 \\
YSU & 850.0 & -6.9 & 126.16 & -15.2 \\
Ensemble & 750.0 & -17.8 & 130.71 & -12.1 \\
\hline
\end{tabular}

Examining the individual ensemble member forecast (Figure 6) shows that all the members made forecasts similar to the control in terms of the areal coverage of the heaviest precipitation. Thus, many of the areal coverage forecasts of heavy precipitation were under-forecast by more than 10\% (Table 3), regardless of the boundary layer, convective, or microphysics schemes. The areal coverage of heavy precipitation produced by the BJMC and KFC schemes (Figure 6(a), Figure 6(d), Table 3) compared most closely with the control (Figure 5(a)), while the FER and TKE schemes (Figure 6(b), Figure 6(e), Table 3) was closest to the observed (Figure 5(b)). The former schemes under-forecast the heaviest precipitation amounts, and the heaviest amounts in Figure 6(a), Figure 6(d) were near the coast as in the observed. These schemes also predicted local precipitation maxima in western North Carolina associated with the Appalachian Mountains as in the observed. This might be because the BJMC microphysics scheme was designed to handle precipitation associated with tropical systems and simulates tropical cyclone tracks well [25] [26] [27]. Also, the KFC scheme does simulate convection very well whether in the tropics or mid-latitudes [28] [31] [32]. Additionally, both schemes produced slightly higher maximum precipitation amounts than the control run and closer to the observed near the coast (Table 3) and the mountains (over-forecast). The TKE scheme performed very well in comparison to the observed precipitation since it was designed for marine boundary layers.

The heaviest observed precipitation was close to $1000 \mathrm{~mm}$ and these areas were on the coast especially near the border of the Carolinas. The schemes that produced similar amounts of precipitation were the GFC and KFC convective schemes (Figure 6(c), Figure 6(d)) (Table 3), respectively, and the YSU planetary boundary layer scheme (Figure $6(\mathrm{~g})$ ). Each of these produced more than $800 \mathrm{~mm}$ of precipitation maxima, but northward of the observed maximum 

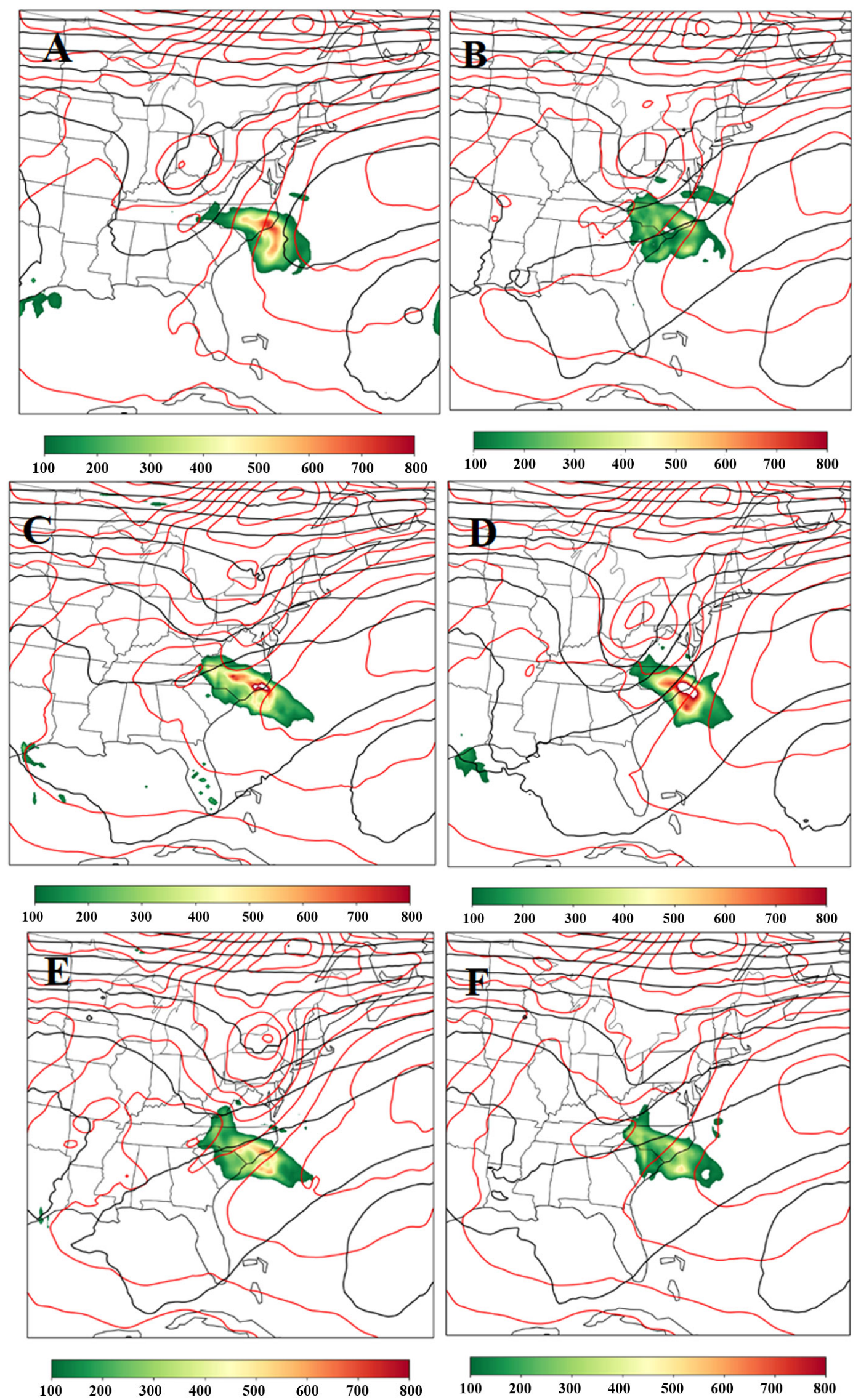


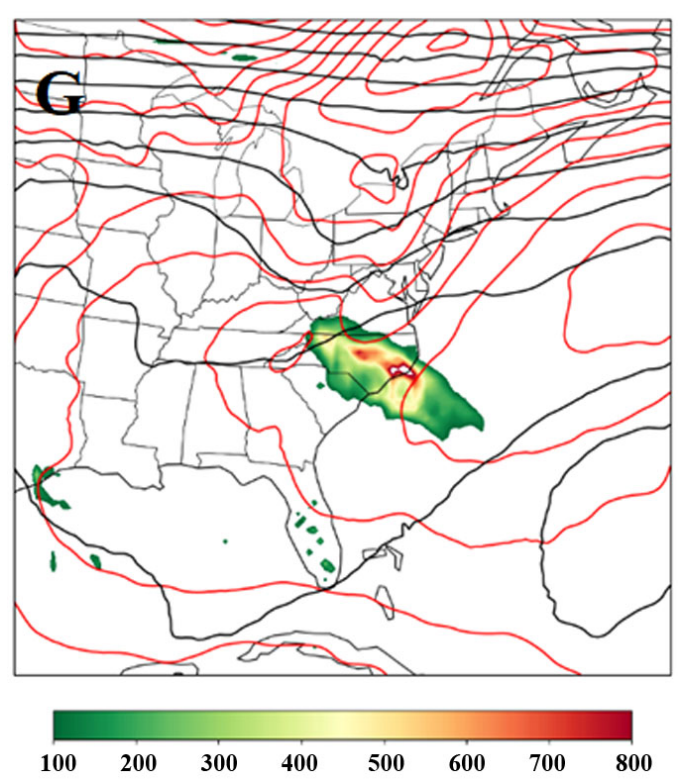

Figure 6. As in Figure 5(a), except for the (a) BMJC, (b) FER, (c) GFC, (d) KFC, (e) TKE, (f) WDM6, and (g) YSU, respectively.

along the coast. Each of these schemes produces an elongated maximum that extends well into North Carolina, which was not observed. It is not surprising that these two convective schemes produce better precipitation amounts near the coast as these schemes include convection that is similar to observed tropical convection [18] [33].

In summary, the WRF-ARW modeled IRE captured the NH wide decrease of IE over the five-day model forecast. The WRF-ARW model domain covered the eastern two-thirds of North America and surrounding environment. The size of this domain is about one quarter that used by [8] and [10] for their studies of blocking anticyclones ( $40^{\circ}$ latitude by $60^{\circ}$ longitude) using IRE. These studies used the smaller domains as they showed that local IRE matched reasonably with the NH IE values. This seems to the case here as well, and may indicate the WRF-ARW is capturing the local NH flow regime transition to a more zonal state as shown in section three. This transition was likely responsible at least partly for the slowing of Florence as it came ashore. The WRF-ARW under-forecast the areal coverage of the heaviest precipitation for most variations of the model tested here, and generally under-forecast the maximum amount precipitation found near the coast and over-forecast the heavy precipitation found inland. Many of the model variations also captured the topologically enhanced maxima observed in western North Carolina. The model forecast using the FER and TKE schemes produced the best area coverage for the heaviest precipitation. Two of the three model runs producing the best maximum precipitation values (YSU and GFC in Table 3) also produced two of the four best IRE tendency forecasts. Thus, for the landfall of Florence, there is some correspondence between those WRF-ARW runs producing the best IRE tendencies (DIRE) and the area coverage or maximum precipitation amounts. However, more study 
would be required in order to determine if this correspondence is true more generally

\section{Summary and Conclusions}

A multi-scale study of the Hurricane Florence landfall during mid-September 2018 was carried out here using the WRF-ARW mesoscale model. This was a major storm, which produced record rainfalls along the Carolina Coast and inland over the southeast USA causing severe economic damage and casualties. The large-scale study was performed using the NCEP re-analyses. The mesoscale study was done using model output from the WRF-ARW over a 120 -h period from 1200 UTC 13 to 1200 UTC 18 September 2018 in which the convective, cloud microphysics, or boundary layer schemes were varied. This period covered the hurricane landfall and stalling over the southeast USA and subsequent flooding.

The key findings were:

- Hurricane Florence began as a classical eastern Atlantic storm and moved toward the northwest around 3 September 2018. The course of the storm became westward after a change in the $\mathrm{NH}$ flow regime from zonal to meridional;

- The storm slowed its forward movement as it came ashore on 14 September 2018 when the NH flow regime was transitioning back to a zonal pattern characteristic of early September The NH IRE was decreasing during the latter stage of the meridional flow regime, but increased as the zonal regime was established;

- The WRF-ARW model control run and ensemble mean captured well the observed NH IRE tendency. However, only the YSU model run matched well the mean IRE tendency and root-mean-square values;

- The model generally under-forecasted the areal coverage of the heaviest precipitation by $10 \%$. The FER and YSU cloud microphysics and boundary layer schemes best captured this area coverage;

- The same model under-forecast the heaviest amounts of precipitation near the coast, and the GFC and KFC convective schemes and the YSU boundary layer) were closest to the coastal maximum;

- Lastly, four of the best model forecasts of IRE tendency also produced either one of the four best areal coverage or coastal precipitation maxima during the forecast period.

\section{Acknowledgements}

The authors would like to thank the anonymous reviewers for their helpful comments in making this a stronger contribution.

\section{Conflicts of Interest}

The authors declare no conflicts of interest regarding the publication of this paper. 


\section{References}

[1] Gibbens, S. (2018) Why Hurricane Florence Was Such a Dangerous Storm. Nat. Geogr.

https://www.nationalgeographic.com/environment/2018/09/news-hurricane-florenc e-east-coast

[2] National Hurricane Center (NHC) (2018). https://www.nhc.noaa.gov/data/tcr/index.php?season=2018\&basin=atl

[3] Lupo, A.R., Li, Y.C., Feng, Z.C., Fox, N.I., Rabinowitz, J.L. and Simpson, M.A. (2016) Sensitive versus Rough Dependence on Initial Conditions in Atmospheric Flow Regimes. Atmosphere, 7, 157. https://doi.org/10.3390/atmos7120157

[4] Li, Y.C. (2014) The Distinction of Turbulence from Chaos-Rough Dependence on Initial Data. Electronic Journal of Differential Equations, 2014, 1-8. https://doi.org/10.1186/1687-1847-2014-85

[5] Li, Y.C. (2015) Rough Dependence upon Initial Data Exemplified by Explicit Solutions and the Effect of Viscosity. https://arxiv.org/abs/1506.05498

[6] Li, Y.C. (2018) Linear Hydrodynamic Stability. Notices of the American Mathematical Society, 65, 1255-1259. https://doi.org/10.1090/noti1743

[7] Dymnikov, V.P., Kazantsev, Y.V. and Kharin, V.V. (1992) Information Entropy and Local Lyapunov Exponents of Barotropic Atmospheric Circulation. Izvestiya, Atmospheric and Oceanic Physics, 28, 425-432.

[8] Athar, H. and Lupo, A.R. (2010) Scale and Stability Analysis of Blocking Events from 2002-2004: A Case Study of an Unusually Persistent Blocking Event Leading to a Heat Wave in the Gulf of Alaska during August 2004. Advances in Meteorolo$g y$, 2010, Article ID: 610263. https://doi.org/10.1155/2010/610263

[9] Schnetzler, A.E., Glisan, J.M., Athar, H., Market, P.S. and Lupo, A.R. (2010) A Comparative Study to Quantify the Sensitive Dependence in Numerical Models for a Developing Low in the Southern Plains. Transactions of the Missouri Academy of Science, 44, 20-28. https://doi.org/10.30956/0544-540X-44.2010.29

[10] Jensen, A.D. and Lupo, A.R. (2013) Using Enstrophy-Based Diagnostics in an Ensemble for Two Blocking Events. Advances in Meteorology, Special Issue: Large-Scale Dynamics, Anomalous Flows, and Teleconnections, 2013, Article ID: 693859. https://doi.org/10.1155/2013/693859

[11] Reynolds, D.D., Lupo, A.R., Jensen, A.D. and Market, P.S. (2019) The Predictability of Northern Hemispheric Blocking Using an Ensemble Mean Forecast System. The Open Atmospheric Science Journal, 13, 13-28. https://doi.org/10.2174/1874282301913010013

[12] Kalnay, E., Kanamitsu, M., Kistler, R., et al. (1996) The NCEP/NCAR 40-Year Reanalysis Project. Bulletin of the American Meteorological Society, 77, 437-471. https://doi.org/10.1175/1520-0477(1996)077<0437:TNYRP>2.0.CO;2

[13] Kistler, R., Kalnay, E. and Collins, W. (2001) The NCEP-NCAR 50-Year Reanalysis: Monthly Means CD-ROM and Documentation. Bulletin of the American Meteorological Society, 82, 247-267. https://doi.org/10.1175/1520-0477(2001)082<0247:TNNYRM>2.3.CO;2

[14] Lupo, A.R., Jensen, A.D., Mokhov, I.I., Timazhev, A.V., Eichler, T. and Efe, B. (2019) Changes in Global Blocking Character during the Most Recent Decades. Atmosphere, 10, Article ID: 00092. https://doi.org/10.3390/atmos10020092

[15] Lebedeva, M.G., Lupo, A.R., Chendev, Y.G., Krymskaya, O.V. and Solovyev, A.B. (2019) Changes in the Atmospheric Circulation Conditions and Regional Climatic 
Characteristics in Two Remote Regions since the Mid-20th Century. Atmosphere, 10, 11. https://doi.org/10.3390/atmos10010011

[16] Lien, G.-Y., Kalnay, E., Miyoshi, T. and Huffman, G.J. (2016) Statistical Properties of Global Precipitation in the NCEP GFS Model and TMPA Observations for Data Assimilation. Monthly Weather Review, 144, 663-679. https://doi.org/10.1175/MWR-D-15-0150.1

[17] Newberry, R.G., Lupo, A.R., Jensen, A.D. and Rodgriges-Zalipynis, R.A. (2016) An Analysis of the Spring-to-Summer Transition in the West Central Plains for Application to Long Range Forecasting. Atmospheric and Climate Sciences, 6, 375-393. https://doi.org/10.4236/acs.2016.63031

[18] Johnson, R.H., Rickenbach, T.M., Rutledge, S.A., Ciesielski, P.E. and Schubert, W.H. (1999) Trimodal Characteristics of Tropical Convection. Journal of Climate, 12, 2397-2418. https://doi.org/10.1175/1520-0442(1999)012<2397:TCOTC >2.0.CO;2

[19] Sunny Lim, K.-S., Hong, S.-Y., Yoon, J.-H. and Han, J. (2014) Simulation of the Summer Monsoon Rainfall over East Asia Using the NCEP GFS Cumulus Parameterization at Different Horizontal Resolutions. Weather and Forecasting, 29, 1143-1154. https://doi.org/10.1175/WAF-D-13-00143.1

[20] Ma, L.-M. and Tan, Z.M. (2009) Improving the Behavior of the Cumulus Parameterization for Tropical Cyclone Prediction: Convection Trigger. Atmospheric Research, 92, 190-211. https://doi.org/10.1016/j.atmosres.2008.09.022

[21] Raju, P.V.S., Potty, J. and Mohanty, U.C. (2011) Prediction of Severe Tropical Cyclones over the Bay of Bengal during 2007-2010 Using High-Resolution Mesoscale Model. Natural Hazards, 63, 1361-1374. https://doi.org/10.1007/s11069-011-9918-1

[22] Gbode, I.E., Dudhia, J., Ogunjobi, K.O. and Ajayi, V.O. (2018) Sensitivity of Different Physics Schemes in the WRF Model during a West African Monsoon Regime. Theoretical and Applied Climatology, 136, 733-751. https://doi.org/10.1007/s00704-018-2538-x

[23] Vaidya, S.S. and Singh, S.S. (2000) Applying the Betts-Miller-Janjic Scheme of Convection in the Prediction of the Indian Monsoon. Notes and Correspondence. Weather and Forecasting, 15, 349-356. https://doi.org/10.1175/1520-0434(2000)015<0349:ATBMJS>2.0.CO;2

[24] Janjić, Z.I. (1994) The Step-Mountain Eta Coordinate Model: Further Developments of the Convection, Viscous Sublayer, and Turbulence Closure Schemes. Monthly Weather Review, 122, 927-945. https://doi.org/10.1175/1520-0493(1994)122<0927:TSMECM>2.0.CO;2

[25] Kessler, E. (1969) On the Distribution and Continuity of Water Substance in Atmospheric Circulations. Meteorological Monographs, No. 32, Springer, Berlin, 88 p. https://doi.org/10.1007/978-1-935704-36-2

[26] Kessler, E. (1995) On the Continuity and Distribution of Water Substance in Atmospheric Circulations. Atmospheric Research, 38, 109-143. https://doi.org/10.1016/0169-8095(94)00090-Z

[27] Lin, Y.-L., Farley, R.D. and Orville, H.D. (1983) Bulk Parameterization of the Snow Field in a Cloud Model. Journal of Applied Meteorology, 22, 1065-1092. https://doi.org/10.1175/1520-0450(1983)022<1065:BPOTSF $>2.0 . C O ; 2$

[28] Nasrollahi, N., Agha, A., Kouchak, J., Li, X., Gao, K., Hsu and Sorooshian, S. (2012) Assessing the Impacts of Different WRF Precipitation Physics in Hurricane Simulations. Weather and Forecasting, 27, 1003-1016. https://doi.org/10.1175/WAF-D-10-05000.1

[29] Grabowski, W.W., Morrison, H., Shima, S.-I., Abade, G.C., Dziekan, P. and Paw- 
lowska, H. (2019) Modeling of Cloud Microphysics. Can We Do Better? Bulletin of the American Meteorological Society, 100, 655-672. https://doi.org/10.1175/BAMS-D-18-0005.1

[30] Gentry, M.S. and Lackmann, G.M. (2006) The Sensitivity of WRF Simulations of Hurricane Ivan to Choice of Cumulus Parameterization. 27 th Conference on Hurricanes and Tropical Meteorology, Monterey, 5-14.

[31] Pattanayak, S., Mohanty, U.C. and Osuri, K.K. (2012) Impact of Parameterization of Physical Processes on Simulation of Track and Intensity of Tropical Cyclone Nargis (2008) with WRF-NMM Model. Scientific World Journal, 2012, Article ID: 671437. https://doi.org/10.1100/2012/671437

[32] Kain, J.S. and Fritsch, J.M. (1993) Convective Parameterization for Mesoscale Models: The Kain-Fritsch Scheme. In: Emanuel, K.A. and Raymond, D.J., Eds., the Representation of Cumulus Convection in Numerical Models, Springer, Berlin, 165-170. https://doi.org/10.1007/978-1-935704-13-3 16

[33] Wang, W. and Seaman, N.L. (1997) A Comparison Study of Convective Parameterization Schemes in a Mesoscale Model. Monthly Weather Review, 125, 252-278. https://doi.org/10.1175/1520-0493(1997)125<0252:ACSOCP >2.0.CO;2

[34] Miller, T.L., Cohen, C., Paxton, J. and Robertson, F. (2009) Comparison of the Effects of RAS vs. Kain-Fritsch Convective Schemes in Katrina Forecasts with GEOS-5. Workshop on High-Resolution Climate Modeling, Trieste, 10-14 August 2009, 10-14.

https:/gmao.gsfc.nasa.gov/pubs/docs/high res climate modeling-2009/Trieste pre sentations/Tuesday/Miller.pdf

[35] Halder, M., Hazra, A., Mukhopadhyay, P. and Siingh, D. (2015) Effect of the Better Representation of the Cloud Ice-Nucleation in WRF Microphysics Schemes: A Case Study of a Severe Storm in India. Atmospheric Research, 154, 155-174.

https://doi.org/10.1016/j.atmosres.2014.10.022

[36] Sunny Lim, K.-S. and Hong, S.-Y. (2010) Development of an Effective DoubleMoment Cloud Microphysics Scheme with Prognostic Cloud Condensation Nuclei (CCN) for Weather and Climate Models. Monthly Weather Review, 138, 1587-1612. https://doi.org/10.1175/2009MWR2968.1

[37] Nolan, D.S., Zhang, J.A. and Stern, D.P. (2009) Evaluation of Planetary Boundary Layer Parameterizations in Tropical Cyclones by Comparison of in Situ Observations and High-Resolution Simulations of Hurricane Isabel (2003). Part I: Initialization, Maximum Winds, and the Outer-Core Boundary Layer. Monthly Weather Review, 137, 3650-3674. https://doi.org/10.1175/2009MWR2785.1

[38] Hong, S.-Y., Noh, Y. and Dudhia, J. (2006) A New Vertical Diffusion Package with an Explicit Treatment of Entrainment Processes. Monthly Weather Review, 134, 2318-2341. https://doi.org/10.1175/MWR3199.1

[39] Xie, B., Fung, J.C.H., Chan, A. and Lau, A. (2012) Evaluation of Nonlocal and Local Planetary Boundary Layer Schemes in the WRF Model. Journal of Geophysical Research, 117, D12103. https://doi.org/10.1029/2011JD017080

[40] Grenier, H. and Bretherton, C.S. (2001) A Moist PBL Parameterization for LargeScale Models and Its Application to Subtropical Cloud-Topped Marine Boundary Layers. Monthly Weather Review, 129, 357-377. https://doi.org/10.1175/1520-0493(2001)129<0357:AMPPFL >2.0.CO;2

[41] Mellor, G.L. and Yamada, T. (1982) Development of a Turbulence Closure Model for Geophysical Fluid Problems. Reviews of Geophysics and Space Physics, 20, 851-875. https://doi.org/10.1029/RG020i004p00851 
[42] Bretherton, C.S., McCaa, J.R. and Genier, H. (2004) A New Parameterization for Shallow Cumulus Convection and Its Application to Marine Subtropical CloudTopped Boundary Layers. Part I: Description and 1D Results. Monthly Weather Review, 132, 864-881.

https://doi.org/10.1175/1520-0493(2004)132<0864:ANPFSC >2.0.CO;2

[43] Park, S. and Bretherton, C.S. (2009) The University of Washington Shallow Convection and Moist Turbulence Schemes and Their Impact on Climate Simulations with the Community Atmosphere Model. Journal of Climate, 22, 3449-3469. https://doi.org/10.1175/2008JCLI2557.1

[44] Ahrens, C.D. and Henson, R. (2019) Meteorology Today: An Introduction to Weather, Climate, and Environment. 12th Edition, Cengage Learning, Boston, 587 p. 